\title{
DESIGN AND ANALYSIS OF A PATCH ANTENNA FOR BLUETOOTH APPLICATION
}

\author{
Ankit Dixit ${ }^{1}$, O.P. Singh ${ }^{2}$, G.R. Mishra ${ }^{3}$ \\ ${ }^{1}$ Department of Electronics \& Comm. Engg., Amity University, Lucknow Campus, India \\ ${ }^{2}$ Department of Electronics \& Comm. Engg., Amity University, Lucknow Campus, India \\ ${ }^{3}$ Department of Electronics \& Comm. Engg., Amity University, Lucknow Campus, India
}

\begin{abstract}
This paper analyzes the patch antenna for Bluetooth application. After analyzing its various parameters the proposed design is created using simulator software HFSS. The parameters considered for the presented design are the gain, radiation pattern, VSWR, and directivity. Through simulation results it was inferred that the design is optimum and the parameters are calculated.
\end{abstract}

Keywords: Patch Antenna, Bluetooth, Gain, Radiation Pattern, VSWR, Directivity.

$* * *$

\section{INTRODUCTION}

Patch antenna is a type of radio antenna; it can be mounted on a flat surface usually rectangular surface. The rectangular sheet can also be referred as patch of metals. To mount this, the large ground surface is required which is called ground plane. The combination is usually placed inside a plastic housing. This protects the antenna from certain damages. The major advantages of patch antenna are its ease in modification, customization and fabrication. In this paper the Bluetooth application has been chosen for the analysis of its various parameters which includes the gain, radiation pattern, VSWR, and directivity; there may be many other parameters for analysis but author is focused some important characteristic of patch antenna. As the frequency of Bluetooth ranges from 2.4 $\mathrm{GHz}$ to $2.458 \mathrm{GHz}$ hence the analysis is carried out in the respective frequency range only.

\section{DESIGN PROCEDURE}

The proposed antenna is designed using FR-4_epoxy material; the substrate with this is drawn by taking the geometry of $12 \mathrm{~mm} \times 9 \mathrm{~mm}$ (Length and Width) with $\mathrm{z}$ dimension as $0.32 \mathrm{~mm}$. The relative permittivity is 4.4 and permeability is of the order of 1 . There are two sheets are used in the presented design viz. lumped port and perfect_E, further the lumped port includes the source terminal with the parameters of 0.495 with $\mathrm{y}$-plane and 0.16 with z-plane. The perfect_E is further divided into three parts which includes feed, ground and the patch terminals. In the feed terminal the orientation is taken as z-axis with $2.5 \mathrm{~mm}$. The ground is characterized as $12 \mathrm{~mm} \times 9 \mathrm{~mm}$ with again $\mathrm{z}$-axis orientation. And finally the patch is given dimension as $7 \mathrm{~mm} \times 2 \mathrm{~mm}$ with $\mathrm{z}$-axis. The following figure- 1 and 2 shows the basic design of the proposed antenna.

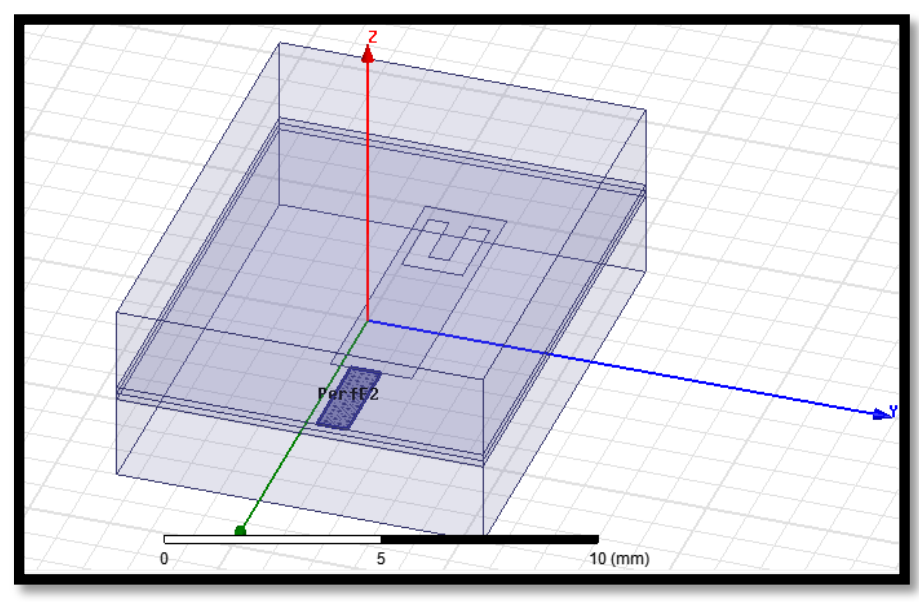

Fig-1 Proposed patch antenna with feed

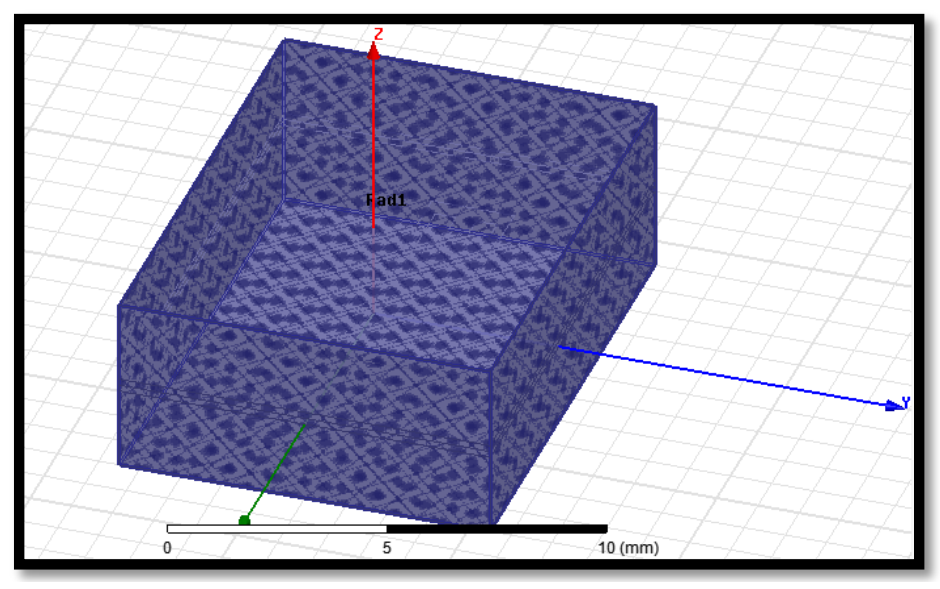

Fig-2 Air boundaries of the antenna 


\section{SIMULATION RESULTS}

The Antenna gain is usually defined as the ratio of the power produced by the antenna from a far-field source on the antenna's beam axis to the power produced by a hypothetical lossless isotropic antenna, which is equally sensitive to signals from all directions. Usually, this ratio is expressed in decibels, and these units are referred to as "decibels-isotropic" (dBi). The following figure-3 shows the antenna gain with setup-1 Last Adaptive parameter and the frequency at $\Phi=0$ and $\Phi=$ 90 degree.

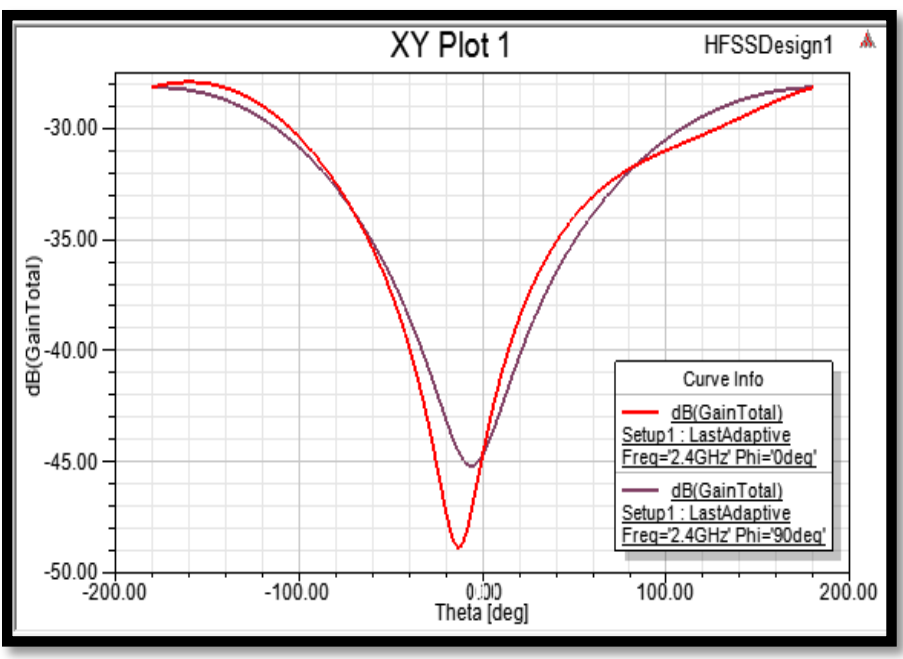

Fig-3 Antenna gain as rectangular plot

The fast sweep type is used and the frequency setup is chosen to be linear count, furthermore the maximum solution is given as 250 with $0.5 \%$ of error tolerance. The radiation plot of antenna gain is shown below in figure-4 as 3D-rectangular plot.

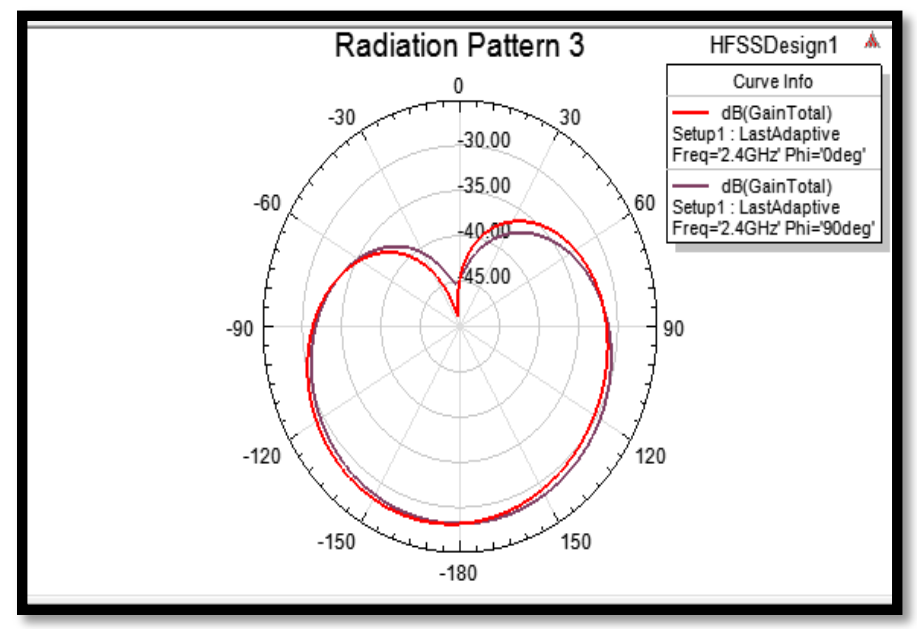

Fig-4 Antenna gain as 3D-Radiation plot
The 3D polar plot of antenna gain is shown in figure-5 and 6 here also the solution setup is last adaptive and the geometry is infinite sphere, the primary sweep is phi and the secondary sweep is theta the magnitude of $\mathrm{db}$ (Total Gain) is measured and the real plot report is obtained.

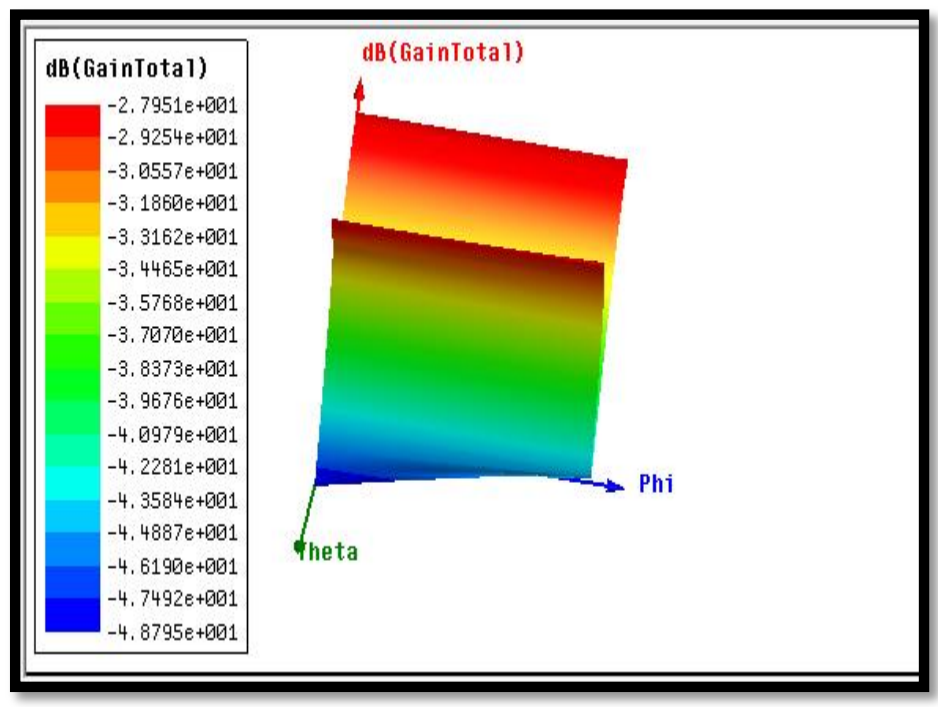

Fig-5 Antenna Gain as 3D polar plot - 1 .

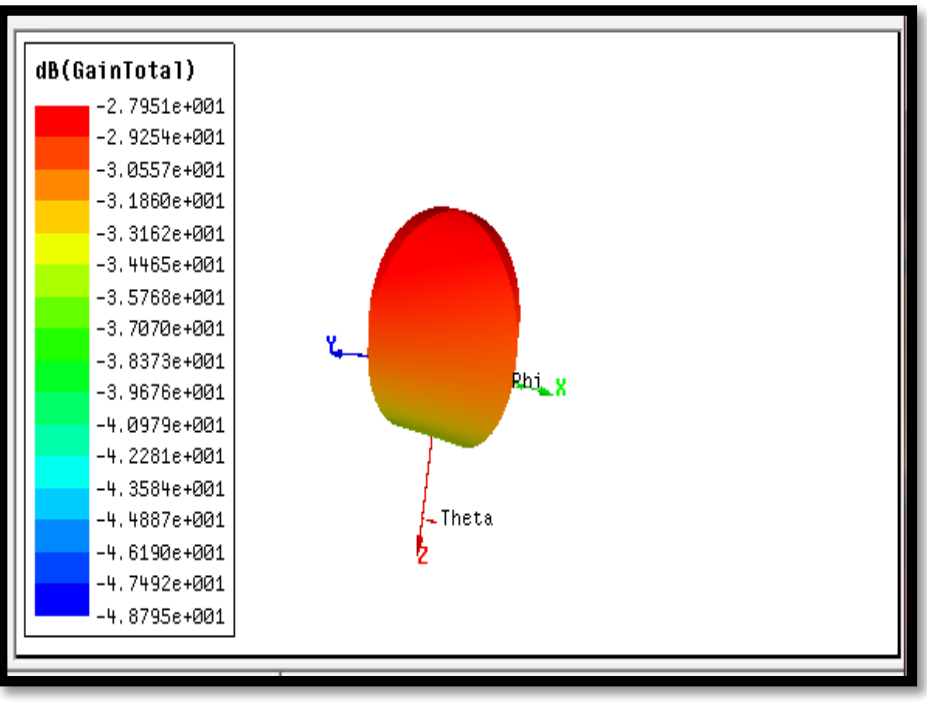

Fig-6 Antenna Gain as 3D polar plot -2 .

Now the parameter considered for the simulation is directivity. Directivity is a figure of merit for an antenna. It measures the power density the antenna radiates in the direction of its strongest emission, versus the power density radiated by an ideal isotropic radiator (which emits uniformly in all directions) radiating the same total power. The following figures- 7 and 8 show the various simulated representation of directivity. 


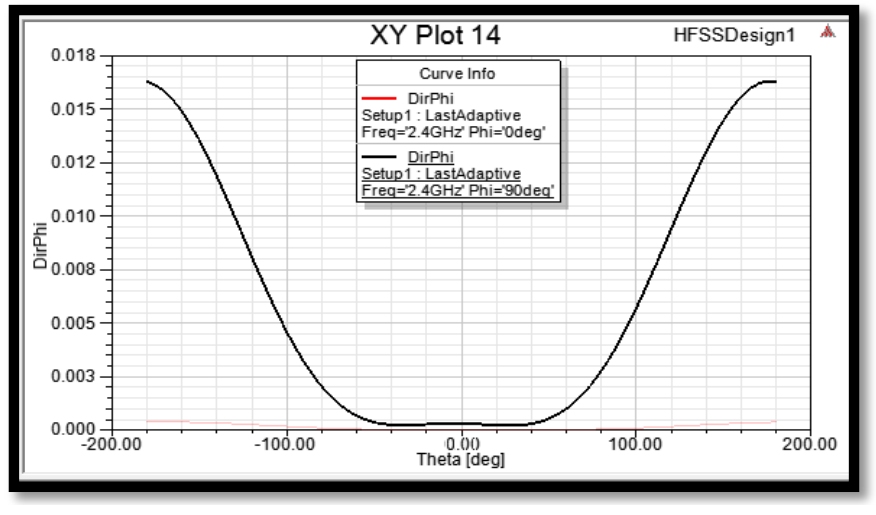

Fig-7 Antenna directivity in rectangular plot

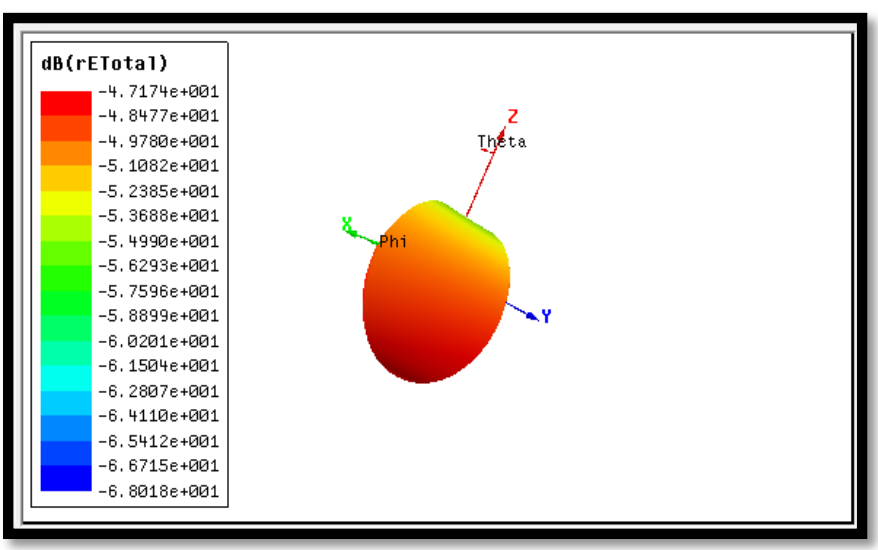

Fig-8 Antenna directivity in 3D-polar plane

The next parameter for consideration is the VSWR. Voltage Standing wave ratio (VSWR) is the ratio of the amplitude of a partial standing wave at an antinode (maximum) to the amplitude at an adjacent node(minimum), in an electrical transmission line. The figure-9 shown below is for VSWR measurement.

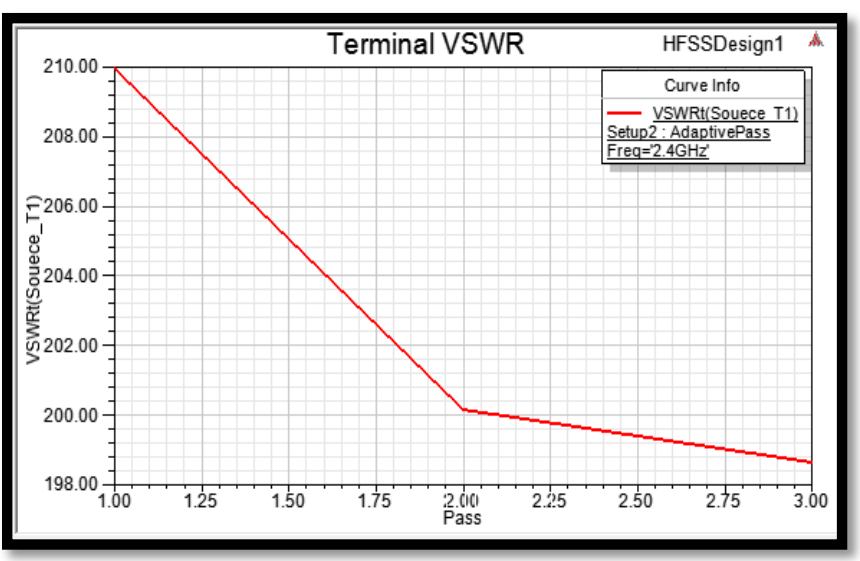

Fig- 9 Terminal VSWR of proposed antenna
The terminal S-parameter and the smith chart of the proposed antenna are shown in figure-10, 11, and 12 respectively.

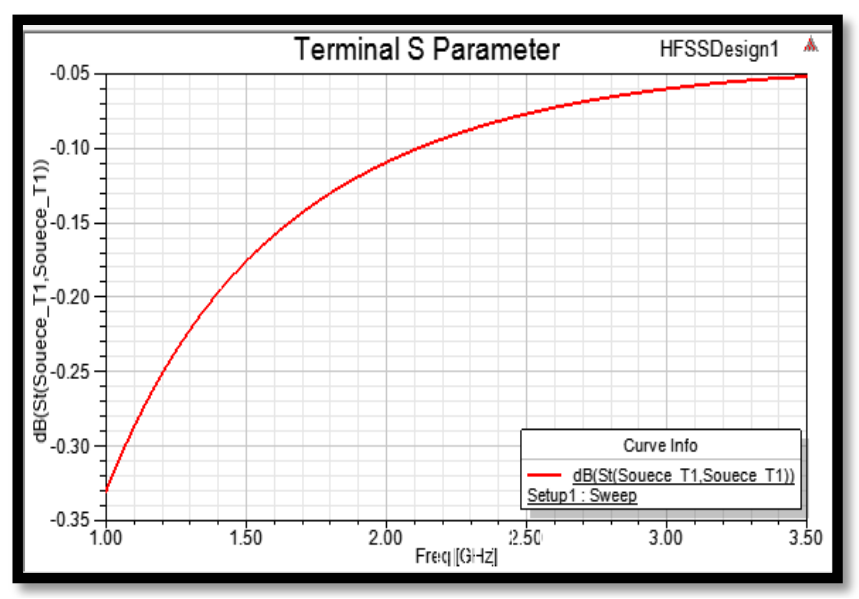

Fig-10 Terminal S-parameter with sweep type

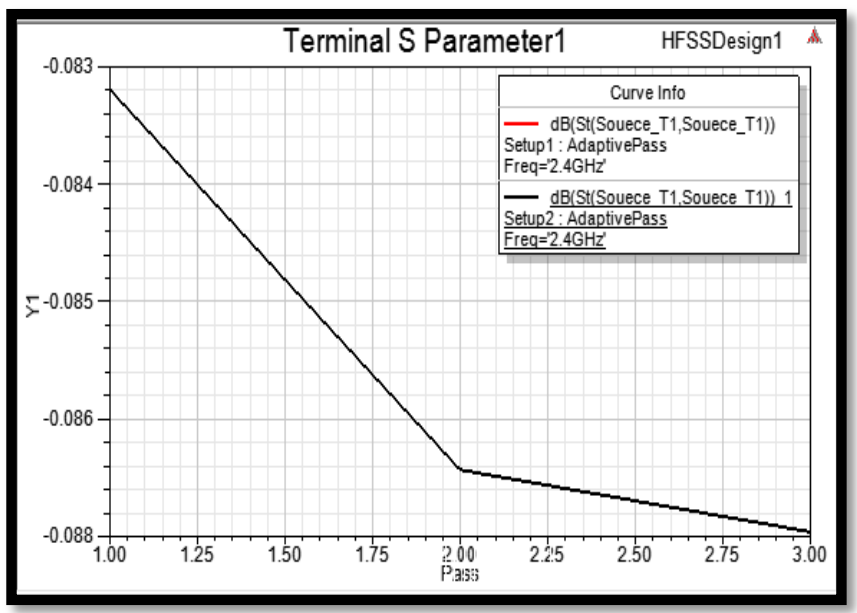

Fig-11 Terminal S-parameters with adaptive type

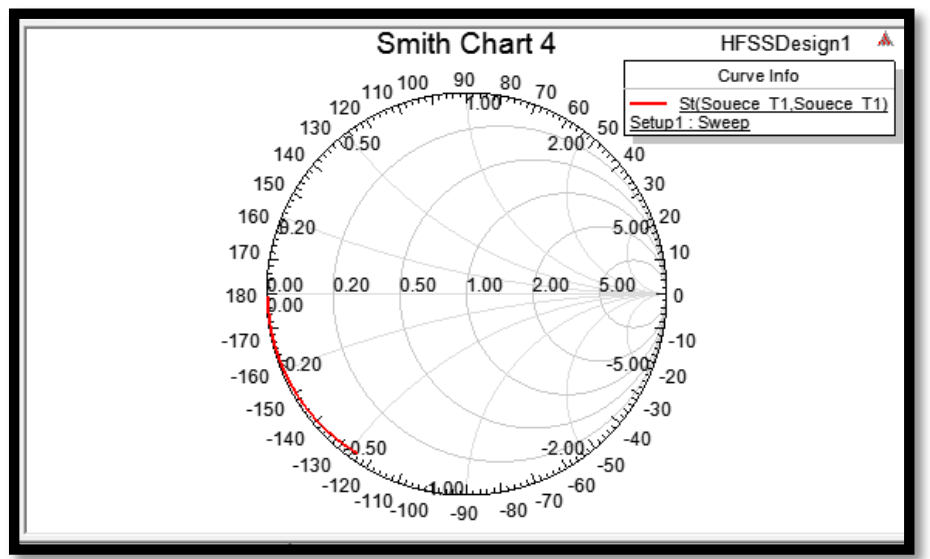

Fig-12 Smith chart of proposed antenna 
The convergence of the proposed antenna by solving the interpolating type sweep-1 with fast adaptive setup as port P1 is represented in figure-13 as shown below. After analyzing the plot it is clear that the proposed antenna converged appropriately for the specified values and parameters.

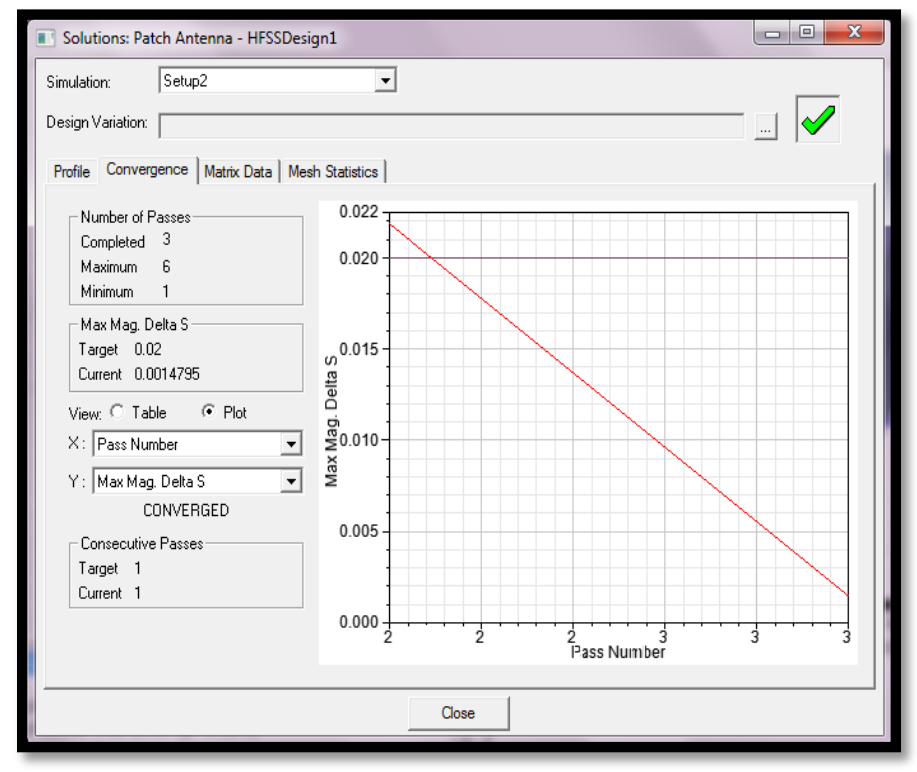

Fig-13 Convergence of proposed antenna

The antenna and its other far field quantities viz. radiation patterns are analyzed and the obtained simulation results are shown below in figure-14 and 15.

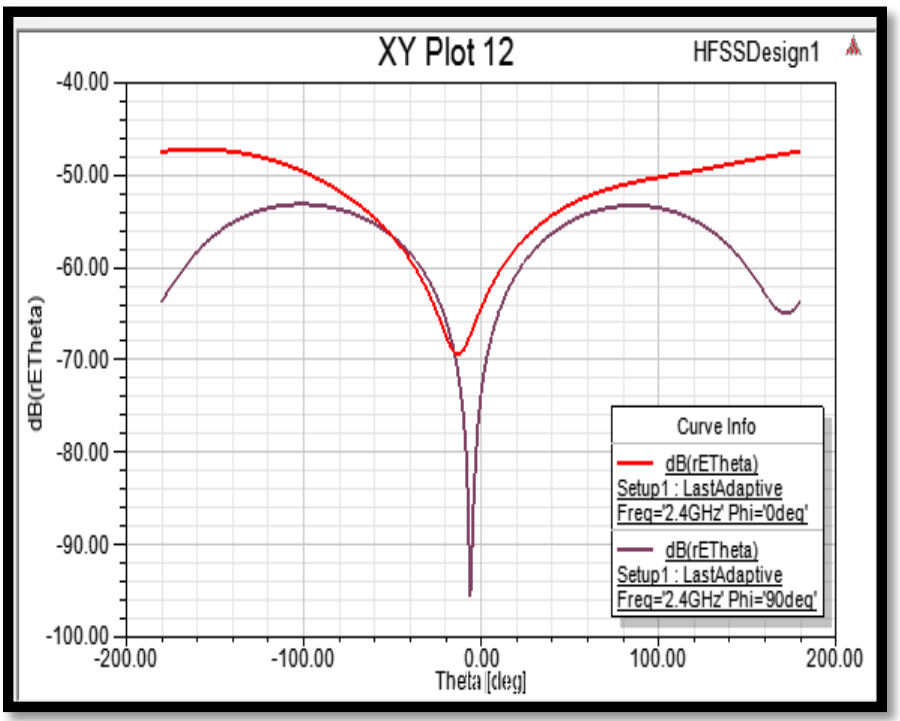

Fig-14 Antenna rE(theta) in rectangular plot

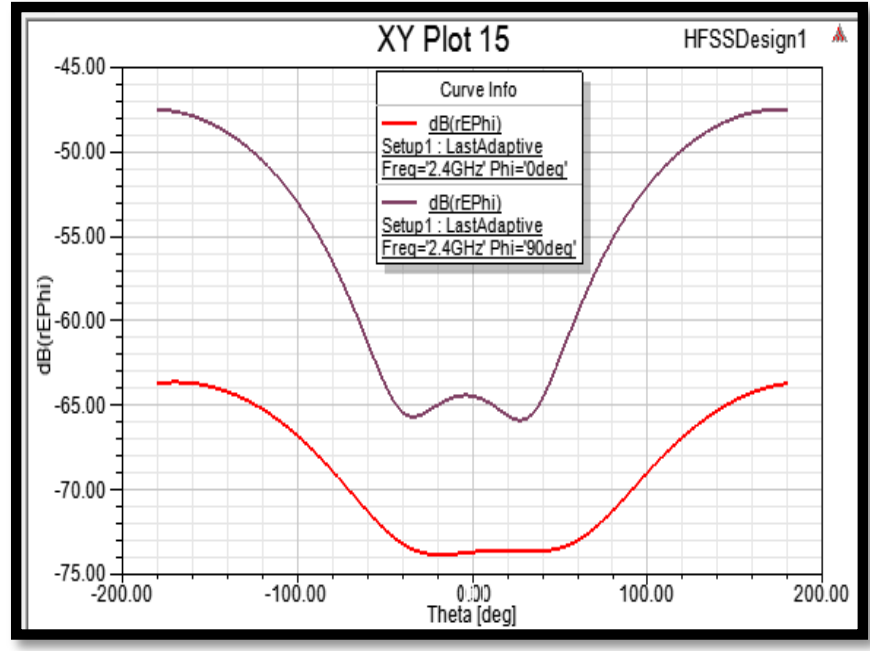

Fig-15 Antenna rE(phi) in rectangular plot.

\section{CONCLUSIONS}

In this paper the novel design of microstrip antenna is proposed. The parameters of analysis were the gain, VSWR, directivity, and the radiation pattern. The values can be easily seen from the respective plot. After analyzing the simulation results it was concluded that the optimized and improved results were obtained. And since the frequency chosen in this design was $2.4 \mathrm{GHz}$ hence this design is appropriate for the Bluetooth application.

\section{REFERENCES}

[1] Abd-Elrazzak, M.M. et. al., "Design of circular patch antennas for bluetooth, HIPERLAN, and X band (8.4 $\mathrm{GHz}$ ) applications", IEEE International Symposium on Antennas Propagation and EM Theory (ISAPE), Dec. 2010, pp. $236-239$.

[2] Wei Zhou et. al., "Planar monopole antenna with Archimedean spiral slot for WiFi/Bluetooth and LTE applications", IEEE Loughborough Antennas and Propagation Conference (LAPC), Nov. 2013, pp. 186 189.

[3] Abd-Elrazzak, M.M et. al., "A design of a circular microstrip patch antenna for Bluetooth and HIPERLAN applications", IEEE 9th Asia-Pacific Conference on Communications, Sept. 2003, pp. 974 - 977.

[4] Awad, N.M. et. al., "Bluetooth/uwb circular patch antenna with dual band notches", IEEE conference of Applied Electrical Engineering and Computing Technologies (AEECT), Dec. 2013, pp. 1 - 4.

[5] Saluja, R. et. al., "Analysis of bluetooth patch antenna with different feeding techniques using simulation and optimization", IEEE International Conference on Recent Advances in Microwave Theory and Applications. Nov. 2008, pp. $742-744$. 
[6] Yi-Chieh Lee et. al., "A High printed antenna at 2.4$\mathrm{GHz}$ operation", IEEE Asia-Pacific Microwave Conference, Dec. 2008, pp. 1 - 4.

[7] Liang-Che Chou et. al., "Uni-Planar Dual-Band Monopole Antenna for $2.4 / 5 \mathrm{GHz}$ WLAN Operation in the Laptop Computer", IEEE Transactions on Antennas and Propagation, Volume: 55, Issue: 12, December 2007, pp. $3739-3741$.

[8] Thomas A. Milligan, "Modern Antenna Design", John Wiley \& Sons, 2nd Edition, 2005

[9] Zhijun Zhang, "Antenna Design for Mobile Devices", John Wiley \& Sons, 2011

[10] Balanis, "Antenna Theory: Analysis and Design", John Wiley \& Sons, 2nd Edition 2007.

[11] Constantine A. Balanis, "Antenna Theory: Analysis and Design ”, John Wiley \& Sons,3rd Edition, 2012.

\section{BIOGRAPHIES}

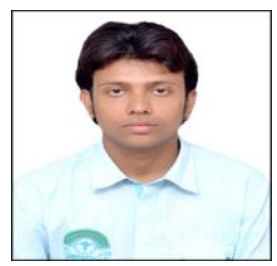

Ankit Dixit, is presently pursuing his M. Tech. studies in the Department of Electronics and Communication Engg., Amity University Uttar Pradesh, Lucknow Campus. He received his B.tech. Degree in Electronics \& Communication Engineering from Institute Of Engineering and Technology, Uttar Pradesh Technical University, in 2011. He has presented several papers in the national conferences. His research area of interest includes antenna design, microwave circuits, digital communication and RF circuits.

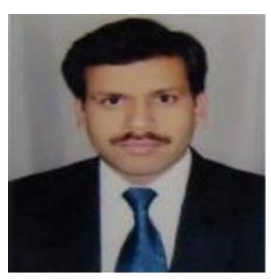

Dr. O. P. Singh obtained his Ph.D. in Electronics Engineering from IIT, BHU. He is presently working as Professor and Head of Department of Electronics \& Communication Engineering, Amity School of Engineering \& Technology, Amity University Uttar Pradesh Lucknow Campus. He is life member of Indian Society of Remote Sensing (ISRS) and Material Research Society of India (MRSI).He has presented several papers in National Seminar/Conferences and also published papers in National/international Journals. His area of interest includes Microwave Remote Sensing Digital System, Signal Processing.

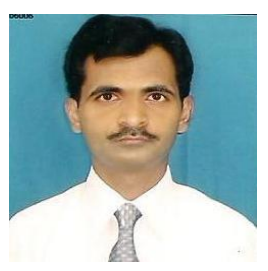

Dr. Ganga Ram Mishra obtained his M.Sc. Electronics degree from Gorakhpur University and $\mathrm{Ph}$. D in Electronics from Avadh University. He has over eleven years experience and presently working as faculty members in Department of Electronics \& Communication Engineering, Amity School of Engineering \& Technology, Amity University Uttar Pradesh Lucknow Campus. He is life member of Institution of Electronics \& Telecommunication
Engineers (IETE), Material Research Society of India (MRSI) and member of IET, UK .He was actively involved in foundation of Professional Activity Center IETE Gorakhpur and worked as elected member of IETE Lucknow Center during 2008-2010 and nominated as local center nominee for IETE Students' Forum (ISF) at Amity University Lucknow Campus. He has presented several papers in National Seminar/Conferences and published papers in National/international Journals. His area of interest includes Digital System Design, Microprocessor Based System Design, Signal Processing, Embedded Systems and VLSI Design. 